\title{
The Challenges Encountered By County Goverments In Kenya During Budget Preparation
}

\author{
Keziah Wangui Mugambi and Ms. Fridah Simba Theuri \\ Jomo Kenyatta University of Agriculture and Technology (JKUAT)-Kenya.
}

\begin{abstract}
The research was centered on the challenges encountered by county governments in budget preparation in Kenya, using Kilifi county as a case study. In carrying out the research, objectives were formulated to find out if budget preparation procedures and proper planning were being adhered to at the counties and the extent to which politicians influenced the budget preparation process. Descriptive analysis was used to analyze the data collected, and from the conclusion, it was found that budget preparation procedures are in place at the counties and being adhered to, however, political influence and public participation affected the budget preparation process, and to avert this, the researcher recommended that public participation be enhanced at the county level by introduction of systems. Publicity should also be enhanced and efforts made to incorporate the views of the public in the budget, as well as enhancing capacity building within the county treasury staff, as the central government makes efforts to deploy staff, to assist the counties in budget preparation.
\end{abstract}

Key Words: Budget, Planning, Public participation and Politics

\section{Introduction}

Sabahi (2013) explains that the Kenyan Budget Controller on $13^{\text {th }}$ August 2013 had given county governments two weeks to revise their budgets after a report from the Commission on Revenue Allocation (CRA) revealed that 25 of Kenya's 47 counties faced significant budget deficits. The controller of budget could not start releasing money to a county that had shown a very big deficit, because it was not clear how the deficit would be closed? She explained that If they released the allocation from the national government and the county ran out of money, it would not even be able to pay salaries.

Similarly, Ustawi 2013 also explains that in May 2013, the COB was steadfast in demanding that the county governments immediately implement lawful internal checks and balances in accordance with the Public Finance Management Act of 2012, over County Funds. The office of the COB and that of the transition authority would do well therefore, to join forces and stand up to political intimidation from a section of Governors and Senators and which reached a crescendo in August 2013, calling for hasty devolution of functions and the funds destined for the Counties. Meanwhile, the Treasury too, was not spared either and found itself at the end of accusations by a section of Governors after it insisted that county governments also implement its Integrated Financial Management Information System, IFMIS. These standoffs between key stakeholders, threatened, the smooth operations of county finances.

\section{Statement Of The Problem}

Kiriria (2013) argues that as Kenya starts to implement devolution, debate rages on whether funding from National Exchequer is adequate or not. He also argues that there must be an effective PFM system at the county level to ensure successful management of the public sector and the economy.

World Bank (2012) recommends that guidelines and templates need to be developed to guide the formulation of county budgets. More so the World Bank advocate for a country-wide chart of accounts for preparing, executing and reporting the budget. In addition to this, the counties would be expected to develop adequate PFM, Human resource and service delivery capacity.

World Bank (2012) acknowledges that public participation will only be meaningful if choices made are translated into spending hence the need to strengthen planning and the budget process. On the contrary, this is not being fully implemented as reflected in the 2013/14 national budget preparation process where only a few people from selected counties were consulted, which is far below the stipulations in the PFM. (The Institute of economic affairs 2013) The study will hence be geared towards finding out if proper planning is being incorporated in the county budget preparation process.

\section{OBJECTIVES OF THE STUDY}

i. To assess effects of non- adherence to the budget preparation process.

ii. To evaluate the consequences of failing to plan during the budget preparation process.

iii. To determine effects of political influence in the budget preparation process. 
iv. To find out how lack of public participation affects the budget preparation process.

\section{Significance And Scope Of The Study}

The focus of this research is to find out the challenges encountered by county governments in budget preparation. There has been great controversy on the validity of county budgets and as such, my concern will be to establish the factors leading to county budgets being in unacceptable formats. This study will try to find out the effects of non-adherence to the budget preparation process and consequences of failing to prepare a plan during the budget preparation.

Similarly, the research will also find out the effects of political influence and lack of public participation in budget preparation process. Literature review on these factors will also be analyzed so as to derive the research gaps that the researcher will focus on. The research will be restricted to Kilifi County where the data will be collected from the staff within the twelve departments of the county, analyzed, so as to come up with the recommendations.

\section{Traditional budgeting}

\section{Budgeting}

Traditional budgets usually focus on a fixed timed period, usually coinciding with the company's fiscal year in which forecasting values remain static, and are not changed during the life of the budget-cycle. Voigt (2010) quotes Rivero \& Emblemsvag who emphasize that the traditional incremental budgeting process begins with last year's continuing budget figures as the base budget, and the numbers are then adjusted to reflect inflation, growth, changing conditions and other information gathered from financial forecasts for the upcoming fiscal year. Similarly, goals according to which performance evaluation is completed are set top-down and senior management for example sets performance objectives — such as revenue and profitability ratios and imposes these goals on the rest of the organization.

\section{Modern budgeting}

It creates a rolling budget, which reflects a budget that is continuously updated so that the time frame remains stable while the actual period covered by the budget changes. Similarly, budgeted revenues and costs are adjusted during the budget period according to predetermined variances between the budgeted and actual output and revenue. Employment of zero based budgets (ZBB) or just in-time budgeting, tries to counter today's extreme uncertainty, and therefore, the budgeting process begins from the ground up, as though the budget was being prepared for the first time.

In addition to this, Voigt (2010) reiterates the word of Brown, Evans \& Moser, who explains that the budget starts with a base budget of zero and calculates the costs of running each program from scratch, on condition that each cost associated with running a program must be justified before it can be included in the budget. Consequently, goals to evaluate performance are set in a participative approach where those responsible for achieving the budget goals are included in setting them.

\section{Trends in budgeting}

De Waal describes emerging trends in budgeting as being composed of activity based budgeting (ABB) and beyond budgeting (BB), in which the former uses activity-based concepts to convert the estimated demand for products and services into activity requirements using activity consumption rates, and then translates activity requirements into resource requirements using resource consumption rates". On the other hand the B-B technique replaces rigid budget-based performance evaluations with flexible benchmarked based comparisons. (Voigt 2010)

\section{Budget Process}

Brookson (2000) explains that a budget model helps one get it right with budgets the first time as well as improves its quality and failure to properly plan and monitor budgets leads to their failure and therefore to avert this, there is a need to write and monitor budgets. In fulfilling this, the PFM Act 2012 stipulates all the processes, policies, the personnel required for preparation and approval of the same budget as well as the conditional ties that need to be met to come up with the budgets. In the same line of thought, organizations that strive to maintain efficiency, effectiveness and equity may become so bound up with rules and forget the human needs.(Naylor 2002).

Pierre and Peters (2011) recognizes that for an effective budget the budget must first of all be adopted by a duly constituted authority, and it must be adhered to. The government must avail the information on budgets to the public, which must have been involved in its preparation and despite the fact that revenue is always limited; the available resources must be matched with the expenditure. Availability of a functioning 
accounting system on the other hand, cannot be emphasized as well as effective auditing system to guarantee an efficient budget preparation process.

In the preparation of the national budget, the debate and approval process in parliament is given a lot of emphasis through media coverage, together with the budget reading day which is also graced by the head of state, contrary to other stages of the budget process. The success of the entire budget process is dependent on the success of each and every phase of the budget process (Mwenda and Gachocho 2003).

\section{Financial Planning}

Rose and Lawton (1994) in their book quotes Wedgewood-Oppenheim who describes planning as a process whereby aims, factual evidence and assumptions are translated by a process of logical argument into appropriate policies which are intended to achieve aims. They advise that since public sector organizations take decisions and make plans in turbulent environments that are prone to be affected by internal dynamics of the organizations and views from various stakeholders as well as external factors, planning has to be dynamic in the formulation and implementation of budgets.

Bose (2012) explains that financial planning helps to determine the objectives, policies, procedures and programs to deal with the financial activities of an organization. As a result of the planning the organization is able to ensure availability of adequate capital, liquidity of the firm throughout the year minimization of cost and proper financial control. This would only be achieved if the organization would establish its objectives, estimate the capital required, determine the capital structure and formulate policies such as credit and debt policies.

On the contrary the notion of a planned strategy being translated in such a prescriptive and precise way that it will be replicated in the detail of organizational action is unrealistic. Johnson, Scholes and Whittington (2006) also argue that such plans will be translated differently by people in the organization. They however advise that guidelines and rules are required, which should not be so prescriptive and constraining as to prevent interaction, sharing, questioning and innovative behavior. In addition to this, proper systems, controls, leadership, team membership skills and training in effective thinking helps to stimulate ideas and keep brains fit for innovative thinking. (Adair 1990) without there would be chaos

Wekesa (2006) explains that development planning is universally practiced today despite the fact that it is prone to failure stimulated by poor technical design of plans due to lack of expertise and inadequate information, unrealistic targets and lack of commitment from some governments that plan to please donors by implementing projects, at the expense of the community. Similarly, external factors such as impact of rational economies or cross border integration of markets, conflicts between different stakeholders and inadequate communication and consultation between public and private sector leaders during the planning phase, can render a plan obsolete for instance the current disagreement between the national assembly and senate may hinder the revenue distribution plan.

Previously in Kenya, budgeting, policy and planning have not been conducted in an entirely integrated and comprehensive manner which has resulted into inconsistencies and incoherencies in Kenya's development platforms. The MTEF model has now been adapted for use, which is designed to instill discipline in managing and planning national resources by establishing an explicit link between the policy framework and the budgetary process. It seeks to bring a better integration of policy reforms, budgeting and expenditure management and attempts to link sector objectives to national priorities and thereby achieve greater result from existing level of resources. (IEA 2013)

Similarly, for the MTEF to work it requires commitment from all levels to ensure that allocations once made on the basis of policy priorities are not adjusted to respond to political interests. Managers need to be firm in ensuring that donors do not distort the MTEF outlines, as well as revenue collection is enhanced to avoid recurrent shortfalls that would occasion continuous spending adjustments.

\section{Budgeting And Politics}

Stillman II (2010) describes budgets as political documents reflecting through the allocation of funds, the ultimate desires, interests and power of various groups within the body politic as expressed by elective legislative bodies. In setting up annual budgets, various political participants engage in log rolling comprises and bargains to create a document that by and large mirrors the current priorities of locality, state or nation.

Budgets are termed as political because first and foremost, they reflect choices about what services the government should provide and what the citizens are entitled to as members of society and determine who gets what. They also reflect the relative proportion of decisions made for local and constituency purposes and for efficiency, effectiveness and broader public goals and in relation to this it portrays the degree of importance legislators put on satisfying their constituents and legislators willingness to listen to interest group demands.

Budgets on the other hand provide a powerful tool of accountability to citizens who want to know how the government is spending their money and if government has generally followed their preferences, hence linking the citizens' preferences with the governments' outcomes. Similarly, the budget reflects how the 
government redistributes wealth upward or downward through the tax system, therefore reflecting the relative power of different individuals and organizations to influence budget outcomes. It provides a picture of the relative power of budget actors within and between branches of government as well as the importance of citizens in general and specific interest groups.

In all these ways public budgeting is political and as such, an important and unique arena of politics because of the specific policy issues reflected in the budget, scope of government and wealth distribution.

\section{Public Participation}

Commonwealth secretariat (2002) acknowledges that pressure for change within the public service must be matched by outside pressure and this requires a public that is confident in its dealings with the public service and a public that knows the standards of performance that the service has set for itself. Similarly Pierre and Peters (2011) argue that the government should have capability of collecting information on preferences of electorate, in the absence of which it would be difficult to allocate resources efficiently.

International government and non-governmental agencies realized more and more that the main reason of many unsuccessful development projects was and still is the lack of active, effective and lasting participation of the intended beneficiaries. Community participation is an important aspect of the vision 2030, because, the critical cornerstones of the social and economic pillars is devolution. It is anticipated that policy-making, public resource management and revenue sharing and as especially as devolved funds become key drivers of development communities will need to be actively engaged so that there is better targeting of resources. In addition to this, there is also a need for a depend and enhanced consultation and information sharing process in the budgeting, implementation and monitoring and evaluation aspects in development projects. (Barasa and Eising: 2012)

Johnson, Scholes and Whittington (2006) explain that the owners of an organization are not only those who have a stake in it and hence interaction between the organization and other stakeholders should be enhanced and the greater it is, the more will new ideas and innovations be received. The stakeholders would comprise of Institutional shareholders such as asset managers of pension funds, bankers, suppliers, employees, community within the vicinity and the customers. In conclusion therefore, they advocate for managers to be conscious of the financial impact of the strategies implemented on various stakeholders.

Similarly, in their book (Barasa and Eising: 2012) quotes Butterfoss et al who postulates that people only participate in processes that are beneficial to them, and in instances where the benefits outweighs the costs that are entailed. The benefits include networking opportunities, access to information and resources, personal recognition, skill enhancement and a sense of contribution and helpfulness in solving community problems. On the contrary the costs they would be required to incur would include contribution of time required plus the skills and resources. Thus a balance needs to be made so that any effort towards community participation in local governance has a net benefit for participants

Although a small percentage of the corporate sector indicated having being requested to submit their budget proposals, they were rarely invited for discussions on such proposals and their incorporation into the national budget was minimal. Consequently it is therefore important that advocacy, capacity building and network development at all levels of the budget phases be given high priority, since lack of or late communication from the treasury to the stakeholders was cited as the major challenge in public participation. (Mwenda and Gachocho 2003).

(Barasa and Eising: 2012) in their book quotes a report from World bank 2005, where it was observed that there is always a tendency to involve only a well behaved groups such as professionals, NGOs and allies who will not question the activities being undertaken, thus leading to misplaced projects and a displeased community. Despite this, very low priority is given to community participation vis-a vis other activities, as well as the information feedback system hence posing challenges to the public participation process.

Eduardo, Camargo and Marcelo (undated) in their report indicate that the city hall of Porto Alegre in Brazil engages it's community in debate and consultation process, through which they define and decide on amounts of income and expense, as well as where and when the investments will be done, which are the priorities and which are the plans and actions to be developed by the Government. The Participative Budget helped to avert corruption and mishandling of public funds, and it has provided efficient spending with results in public works and actions of great importance for the population.

The Participative Budget has also proved that the intention of having effective tools of participation and the commitment of the Government in doing whatever the population decides is essential to cut the chains and the bureaucratic barriers that separate the society from the State, forming an active and mobilized citizenship. 


\section{Critique Of Existing Literature}

The idea of having planned strategies that have to be translated and used in organizations is unrealistic because its prone to be translated differently by people in the organization .which therefore necessitates formulation of policies, which are not always observed by all, thus leading to ineffective implementation of plans.

Similarly, for the MTEF to work it requires commitment from all levels to ensure that allocations once made on the basis of policy priorities are not adjusted to respond to political interests, but this is watered down by the fact that not all parties are participative to the same. Donors are known for interfering with the outlined plans for development and budgets, because the funds they give always have attached conditions to be met, and hence the manager's efforts to control the budgets fail. In addition to this, local revenue collection is not always enhanced as expected thus leading to revenue shortfalls that necessitate continuous spending adjustments and dependency on donor funding that results in difficulties in budget controls.

Budgeting is seen as negotiations between group of routine actors, bureaucrats, budget officers, chief executives and legislators who meet each year and bargain to resolution and though the process is open and anyone can play and win, the major stakeholders always have their way by manipulating the outcome of the meeting and the process is not always as fair as it ought to be.

Similarly Pierre and Peters (2011) argue that the government should have capability of collecting information on preferences of electorate, in the absence of which it would be difficult to allocate resources efficiently, but the capacity is always lacking to undertake these activities. Interaction between the organization and other stakeholders is expected to be enhanced so as to create avenues for receiving new ideas and innovations but this fails since people are perceived to participate only in processes that are beneficial to them, and the cost they would be required to incur in terms of time, skills and resources makes most of them to withdraw.

Despite all this, Barasa and Eising (2012) indicate that there is always biasness portrayed in choosing the stakeholders to be involved in budget preparation and this is displeasing to many and the fact their views are collected and rarely included in the budgets makes most people avoid the whole process all the same. The bureaucratic processes in the public institutions act as a barrier in encouraging active and mobilized citizenship.

\section{Research Methods}

This research problem was studied through the use of a descriptive design, where a case study of Kilifi county government was looked into, to find out what was happening to county budgets. The results of the study was deemed to be the occurrence in the other counties as well. The researcher issued questionnaires and was a passive observer of what took place at the ground level, to collect quantitative data, which was analyzed quantitatively using descriptive and inferential statistics. In order to identify the challenges faced in County budget process in Kenya, questionnaires were formulated, dropped and consequently picked from the respondents.

The data collected was checked for completeness and data entry was done into the SPSS statistics data editor, to enhance viewing and manipulation, and consequently, the software was used to analyze the data. The results were presented using tables, pie and bar charts for ease of understanding.

\section{Results And Discussions}

This study found out that, the technical teams in the county treasury and related departments had the necessary skills required in budget preparation, as indicated by $92.3 \%$ of the respondents, while only $7.7 \%$ of respondents disagreed. Similarly it was noted by $71.8 \%$ against $28.2 \%$ of the respondents that ample time was being utilised in budget preparation and that the county treasury was found to be having budget preparation procedures in place, as indicated by $94.87 \%$ of the respondents, vis-a-vis $5.13 \%$ of the respondents who did not attest to this. Despite all these, the county treasuries were noted to be adhering to the same procedures, since $92.31 \%$ of the respondents affirmed this, compared to $7.69 \%$, who disagreed.

Public participation in the budget preparation process was being implemented at the county, however the stakeholders were majorly involved in part of the process, as $74.38 \%$ of the respondents affirmed this, while $25.64 \%$ of the population did not agree to this. Various stakeholders whose views were collected complained that their views were not entirely incorporated into the budget as was expected, despite the fact that various calibres of stakeholders from all over the county were consulted, as only $48.72 \%$ of the respondents confirmed full incorporation, while another $48.72 \%$ of the respondents confirmed partial incorporation, as $2.56 \%$ of the respondents agreed that stakeholders views were not have reflected in the draft budgets. 
There are various major idea contributors towards the budget preparation, as the respondents indicated because the politicians contribution is at $25.64 \%$, the stakeholders at $35.90 \%$ and the staff at $30.77 \%$.In addition to this, prioritization of projects was rated at $41.0 \%$ for stakeholders, office projects at $38.4 \%$ while proposals from politicians were at $17.9 \%$

\section{Conclusion}

The expectations were that county budgets would be affected by the various factors considered in the study. However, the county treasury was found to be observing and adhering to the set budget guidelines as per the PFM act, though the planning process was not adequately done and needed to be improved so as to issue a valid platform for preparing the budget. On the contrary, public participation was not done as per the stipulated guidelines, while politicians involvement in the budget process was very high and this affected the budget preparation process by increasing the time spent and prioritization of projects within the budget.

\section{Recommendations}

There should be a well-structured, adequately funded, participatory and people oriented policy on public participation, that the public should be made aware of, so as to enhance their participation. Similarly, both pre and post budget hearings should be done so as to sensitize stakeholders on budget proposals and implementations in order to help them understand the budget process, facilitate development and adoption of sound budget policies in addition to enhancing integration of county priorities into the budget.

On the other hand, the county should implement capacity building to tackle human resource, institutions, legal framework and technical support development to empower them on budget preparation. Capacity building will also help in bringing together staff from various department and enable them own up county activities so as to enable them participate actively, since some departments and ministry feel they are not under the devolved governments and are hesitant to participate in the budget process. There is also need for an all-inclusive budget committee to facilitate continuous collaboration among stakeholders, backed by a functional information system through which information could be easily disseminated, and a recommended software on which the staff should be trained on so as to enhance performance. The county government should incorporate the views of the stakeholders in the budget so as to motivate them to participate in subsequent forums.

The national treasury on the other side should deploy staff on secondment basis to the counties, to assist in the budget preparation process.

\section{Limitation Of The Study}

One of the weaknesses of this study is the fact that county governments are still in their introductory stages, and policies and guidelines to help in the county budget preparation process are being formulated. In addition to this, the challenges encountered in Kilifi county could differ from those encountered in other counties hence, it is not sufficient to assume that the challenges established can be used to measure the manifestation of the crisis among counties.

\section{Scope For Further Research}

This study can be improved to provide more plausible results by investigating the factors hindering implementation of county budgets. This study focused on the challenges encountered by county governments in budget preparation and a study to improve on this should be done to investigate how service delivery at the counties could be enhanced through proper implementation of the budgets, and the factors identified and dealt with.

\section{References}

[1]. Adair, J. (1990). The challenge of innovation. Talbot Adair press. England.

[2]. Alam, M. and Nickson, A. (2008). Managing change in Local governance, Replica press Ltd. India

[3]. Barasa, T. and Eising. W (2012). Reforming Local authorities for better service delivery in developing countries. Institute of Policy analysis and Research. Kenya.

[4]. Bose, D.C. (2012). Principles of management and administration.PHI learning private Limited. New Delhi

[5]. Brookson, S. (2000). Managing budgets. Wing King Tong Co. Ltd. Singapore

[6]. Common wealth secretariat (2002) Current good practices and new developments in Public sector service management. Commonwealth Secretariat. London.

[7]. Eduardo, U.J., Camargo, F.J. and Marcelo, M. ( year not mentioned). The expenses of participative budgets in Porto Alegre. Brazil.

[8]. Institute of Economic affairs (2013). Budget Guide: Budget 2013/14: The onset of the devolved government and the hurdles ahead. Institute of Economic affairs Kenya

[9]. Johnson, G. Scholes, K. and Whittington, R. (2006). Exploring corporate strategy: Text and cases $7^{\text {th }}$ edition. Pearson Education Limited. England.

[10]. Kiriria, N. (2013).Public Management in a county: What the leaders should know. The star Kenya

[11]. Pierre, J. and Peters, B.G. (2011). The handbook of Public Administration. Sage publications Ltd. London.

[12]. Rose, A., and Lawton, A. (1940). Organization and Management in the Public Sector. $2^{\text {nd }}$ edition. Pitman Publishing. London. 
[13]. Kenyan budget controller orders counties to revise budgets.(2013,August 13).Sabahi. Retrieved November 8,2013 from:Sabahionline.com/en_GB/articles/hos/articles/newsbriefs/2013/08/13/newsbrief-09.

[14]. Stillman II,R.J. (2010). Public Administration Concepts and cases. $9^{\text {th }}$ edition. Nelson Education Ltd. Canada.

[15]. Ustawi (2013).Controller of Budget under the New Constitution. Ustawi. Retrieved November 8,2013, from

www.ustawi.info.ke/index.php/government/commissions-and-independent offices/controller-of-budget.

[16]. Voigt, Jan-Martin.(2010). The theory of budgeting and its practical application in German Independent hotels. German

[17]. Wekesa, M.J.W.(2006). Essentials of development planning. Kenya

[18]. World Bank. (2012). Devolution without Disruptions - Pathways to a successful New Kenya Poverty Reduction Economic Management unit Africa Region Kenya 